\title{
POLYMORPHISM OF CYTOCHROME P450, SUPERFAMILY19, POLYPEPTIDE 1 GENE AND RELATED TO AROMATASE ENZYME ACTIVITY IN ACROMEGALY IRAQI PATIENTS
}

\author{
IQBAL HANASH DHEFER ${ }^{1}$, SALMA ABDUL-RUDHA ABBAS ${ }^{1}$, NAJWA SH AHMED ${ }^{2}$ \\ ${ }^{1}$ Department of Chemistry, The University of Al-Mustansiriya, College of Science, Baghdad, Iraq. ${ }^{2}$ Department of Biotechnology, \\ Biotechnology Research, Molecular, and Biotechnology Laboratory, AL-Nahrain University, Baghdad, Iraq. Email: iqbal_defer@yahoo.com
}

Received: 16 February 2017, Revised and Accepted: 30 March 2017

\section{ABSTRACT}

Objective: The objective of the present work was to investigate the association between aromatase enzyme activity and polymorphisms, rs2236722, in exon 2 of cytochrome P450 (CYP), superfamily19, polypeptide 1 (CYP19A1gene) in patients with active acromegaly.

Methods: A total of 120 males and females (age 20-60 years) were enrolled in this study, 60 patients with active acromegaly who have attended the National Diabetes Centre and and Specialist Center for endocrinology and diabetes, Baghdad, from December 2015 to June 2016 and 60 healthy individuals with matches as a control group. From the whole blood, genomic DNA was extracted to perform genotyping analysis and single-nucleotide polymorphism, rs2236722, in the CYP19A1 gene using multiplex polymerase chain reaction technique, and serum aromatase levels were determined using a solid-phase enzyme-linked immunosorbent assay based on sandwich method.

Results: The results show that the aromatase activity levels of patients were a highly significant decrease when contrasted with healthy control groups in both sexes $(\mathrm{p} \leq 0.01)$, and there were summarized positive results of an allele in single-nucleotide polymorphism, rs2236722, were highly significant in TT allele when contrasted with healthy control groups. While revealed that there was non-significant difference in TC allele when contrasted with healthy control groups $(\mathrm{p}>0.01)$.

Conclusion: we conclude that there was associated between CYP19A1 gene polymorphism (rs2236722) with aromatase activity and related to acromegaly patients.

Keywords: Aromatase activity, Single-nucleotide polymorphism, rs2236722, Active acromegaly.

(c) 2017 The Authors. Published by Innovare Academic Sciences Pvt Ltd. This is an open access article under the CC BY license (http://creativecommons. org/licenses/by/4. 0/) DOI: http://dx.doi.org/10.22159/ajpcr.2017.v10i6.17886

\section{INTRODUCTION}

Acromegaly is an uncommon hormonal condition that develops most commonly from benign somatotroph pituitary adenomas; the clinical indications connected with acromegaly are a result of the chronic overproduction of growth hormone $(\mathrm{GH})$ and insulin-like growth factor 1 [1,2]. Systemic complications usually connected with the chronic hypersecretion of GH and insulin-like growth factor 1 (IGF-1) include acromegaly, soft tissue changes, and arthralgia, and comorbidities include type 2 diabetes, hypertension, carpal tunnel syndrome, and sleep apnea [3]. The aromatase cytochrome P450 (CYP) is vital for the biosynthesis of estrogens in few tissues, in particular, the ovary, adipose tissue, and brain [4]. By standards of other CYP genes that encoding the aromatase (CYP19) is extraordinarily significant since it is more than $50 \mathrm{kbp}$ at chromosome $15 \mathrm{q} 21.2$. CYP, superfamily19, polypeptide 1 (CYP19A1) is situated and extends about (123 kb) in length. It contains 9 coding exons and various untranslated first exons whose expression is regulated by tissue-specific promoters [5,6]. In a wide assortment of tissues, aromatase is expressed and it has been found in the brain, placenta, liver, ovary, skin, testis, and adipose tissue [7]. At the transcriptional levels in the brain, placenta, and gonads, the tissuespecific promoters regulate the aromatase gene [8]. The protein result of aromatase gene has so far been found the same despite of the tissuespecific expression patterns of aromatase. The control aromatase gene expression at all levels: mRNA, protein, functional, and enzymatic activity has been considered as important not only for the treatment of breast cancer but also the critical role of aromatase enzyme [9], but as well in males, for example, in the cases of prostate cancers or gynecomastia [10]. In every pituitary tissue, there was an expression of aromatase enzyme inclusive autopsy samples and were most increased in patients with acromegaly than in another adenoma groups. In patients with functional adenoma, aromatase expression was elevated in patients with than without post-operative complete remission. These results suggest that aromatase expression perhaps a useful prognostic marker of pituitary adenomas [11]. Previous studies are examining the associations of selected CYP19A1 variants, such as the polymorphisms in intron 4 and the non-synonymous polymorphisms Trp39Arg (rs2236722) in exon 2 [12]. The aim of this research was to estimate the activity of aromatase in acromegaly patients and compare with a control group and study the genetic polymorphism (rs2236722) for aromatase enzyme (CYP19A1) gene and determine the relation between aromatase activity and the polymorphism of gene CYP19A1.

\section{PATIENTS AND METHODS}

A total of 120 males and females (age 20-60 years) were enrolled in this study, 60 patients with active acromegaly who have attended the National Diabetes Centre and Specialist Center for endocrinology and diabetes, Baghdad, from December 2015 to June 2016 and 60 healthy individuals with matches as a control group. Physicians diagnosed all patients, and the study was approved by the Center Ethical Committee. Blood was collected, each blood sample was split into two fractions. The first fraction was conveyed into a tube containing ethylenediaminetetraacetic acid (EDTA) disodium salt for whole blood for genotyping analysis. The other fraction was separated in plain polyethylene test tube, left to clot at room temperature, then the tube was centrifuged at $704 \times \mathrm{g}$ for 10 minutes, and the sera were separated.

\section{Determination of serum aromatase activity}

Serum aromatase levels were determined using human aromatase kit using a solid-phase enzyme-linked immunosorbent assay based on sandwich method; at a wavelength of $450 \pm 2 \mathrm{~nm}$, the optical density 
is measured by spectrophotometric. The optical density value is proportional to aromatase concentration and then calculated the aromatase concentration in serums by comparing the optical density in the serums to the standard curve.

\section{DNA extraction}

The blood samples are collected in EDTA tubes from patient and healthy control groups. The genomic DNA is extracted from the whole blood by G-Spin ${ }^{\mathrm{TM}}$ total DNA extraction kit.

Detection of rs2236722 gene using multiplex polymerase chain reaction (multiplex PCR)

Achievementofoptimization of PCR reactions was afterseveralendeavors to detect the best annealing temperature and the concentrations of both DNA and primer. Briefly, amplified the genomic DNA by two pairs of primers, forward primer (1/F: 5'- ATCTGTACTGTACAGCACC-3') and reverse primer (1/R: $5^{\prime}$ - ATGTGCCCTCATAATTCCG $\left.-3^{\prime}\right)$, for the $C$ allele, and a forward primer (2/F: 5'-GGCCTTTTTCTCTT GGTGT-3') and a reverse primer (2/R: $5^{\prime}$-CTCCAAGTCCTCATTTGCT- $\left.3^{\prime}\right)$, for the T allele (primers set supplied by the IDT (Integrated DNA Technologies company, Canada). PCR reaction was conducted in $25 \mu$ l of a reaction mixture containing $1.5 \mu \mathrm{l}$ (50-100 ng) of DNA, $5 \mu \mathrm{l}$ of PreMix Master Mix, $0.5 \mu \mathrm{l}$ of (10 Pmol $\backslash \mu \mathrm{l})$ of each primer, and $16.5 \mu \mathrm{l}$ of distilled water. Amplification program was one cycle at $94^{\circ} \mathrm{C}$ for 3 minutes; 35 cycles at $94^{\circ} \mathrm{C}$ for 45 seconds, $58^{\circ} \mathrm{C}$ for 45 seconds, and $72^{\circ} \mathrm{C}$ for 45 seconds; and one cycle at $72^{\circ} \mathrm{C}$ for 10 minutes; the amplified product was subjected to $2 \%$ agarose gel electrophoresis with $1.0 \mu \mathrm{l}$ of red stain dye and $5 \mu \mathrm{l}$ ladder and visualized under UV (Agarose Gel Electrophoresis System MGu-502T-pk, USA) after red-safe staining.

\section{Statistical analysis}

1. Statistical analysis was performed by utilizing the Microsoft Office (SPSS vs. 19) which includes the following mean \pm standard deviation test, correlation coefficient, and $\mathrm{p} \leq 0.01$ was statistically significant. In all studied groups, the total prescient values for the outcomes were performed according to Biostatistics through Daniel in 1987.

2. The statistical analysis system was utilized. The Pearson $x 2$ criterion ( $\mathrm{p} \leq 0.01$ ), 95\% confidence intervals (CI), and odds ratio (OR) tests were employed to compare the polymorphisms of frequencies of CYP19A1 gene between the groups.

\section{RESULTS}

Serum aromatase activity level indices in studied groups Table 1 showed the mean \pm SD of aromatase activity levels expressed as $\mathrm{ng} / \mathrm{ml}$ in serum of 60 healthy individuals (males and females) and

Table 1: Serum aromatase activity levels in studied groups

\begin{tabular}{lllll}
\hline Parameter & Mean \pm SD & & \multirow{2}{*}{ t-test } & p value \\
\cline { 2 - 3 } & Controls & Patients & & \\
\hline Aromatase & & & & \\
activity $n g / \mathrm{ml}$ & & & & \\
$\mathrm{M}$ & $11.209 \pm 0.364$ & $2.836 \pm 1.095$ & -34.807 & $0.000^{*}$ \\
$\mathrm{~F}$ & $23.293 \pm 0.003$ & $2.774 \pm 1.638$ & -51.648 & $0.000^{*}$ \\
\hline
\end{tabular}

*The t-test insignificant at the 0.01 level or less, M: Male, F: Female,

SD: Standard deviation
60 active acromegaly patients (males and females). These results showed that there was a highly significant decrease in aromatase activity levels of male and female acromegaly when contrasted with the control group in both sexes $(\mathrm{p} \leq 0.01)$

\section{Genotyping analysis of rs2236722 polymorphisms}

This study includes extracting DNA from the blood of 60 female and male healthy individuals and 60 female and male patients. Agarose gel electrophoresis checked the quality and integrity of DNA before doing PCR. Genotyped the CYP19A1 rs2236722 single-nucleotide polymorphism (SNP) with a PCR method using two-pair primers. Briefly, 25 nanograms of DNA was utilized for each PCR reaction. Some samples were repeated twice to confirm PCR result. Further subjected the PCR products to $2 \%$ agarose gel electrophoresis and identified the alleles as follows: The T allele was represented by DNA bands with sizes $427 \mathrm{bp}$; the TC allele was represented by DNA bands with sizes $(427,264$, and $200 \mathrm{bp})$ as shown in Fig. 1.

Table 2 summarizes the positive results of allele of multiplex in male and female of sample study (patients and controls). 10 male patients from 30 male patients with the present TT allele (52.63\%) and no current with male control. These results showed that there was a highly significant in TT allele when compared with male control group. While 20 male patients from 30 male patients with present TC allele (48.78\%) and all 30 male controls with present TC allele (50.00\%), these results showed that there was non-significant difference in TC allele when contrasted with a male control healthy group ( $\mathrm{p} \geq 0.01$ ). Moreover, 9 female patients from 30 female patients with present TT allele (47.37\%) and no current with female controls. These results showed that there was a highly significant in TT allele when compared with female control group. While 21 female patients from 30 female patients with present TC allele (51.22\%) and all 30 female controls with present TC allele (50.00\%), these results showed that there was non-significant difference in TC allele when contrasted with female control healthy group $(\mathrm{p} \geq 0.01)$. The $\mathrm{CC}$ allele not presents in all patient and control groups in both sexes.

\section{Allele frequency}

Table 3 summarizes the frequency distribution genotypes of CYP19A1 rs2236722 $\mathrm{T}<\mathrm{C}$ polymorphism and allele frequency in patient and

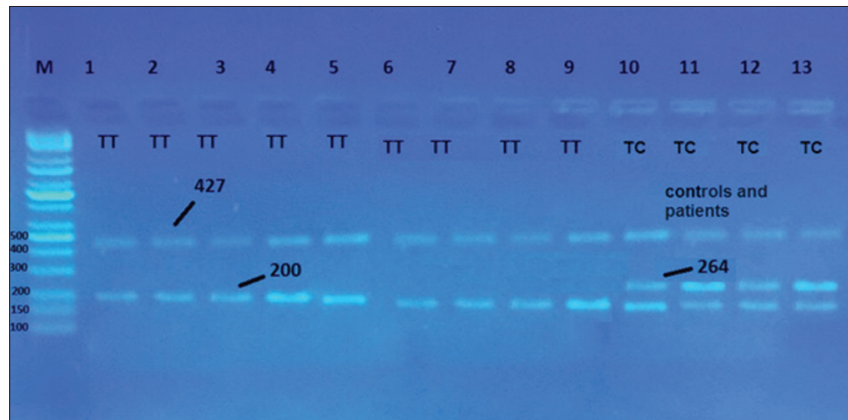

Fig. 1: Genotyping of cytochrome P450, superfamily19, polypeptide 1 rs2236722 $\mathrm{T}<\mathrm{C}$ polymorphisms by multiplex polymerase chain reaction in control and patient samples, Lane M, 500 bp DNA ladder, lanes 1-9, TT genotype (427 and 200 bp), and lanes 10-13, TC genotype $(427,264$, and $200 \mathrm{bp})$

Table 2: Results of multiplex in male and female of sample study (patients and controls)

\begin{tabular}{|c|c|c|c|c|c|c|c|c|c|}
\hline \multirow[t]{2}{*}{ The group } & \multicolumn{2}{|c|}{$\begin{array}{l}\text { Sum of positive results of } \\
\text { allele TT }(200,427)(\%)\end{array}$} & \multirow[t]{2}{*}{ p value } & \multicolumn{2}{|c|}{$\begin{array}{l}\text { Sum of positive results of } \\
\text { allele CC }(264,427)(\%)\end{array}$} & \multirow[t]{2}{*}{$p$ value } & \multicolumn{2}{|c|}{$\begin{array}{l}\text { Sum of positive results of } \\
\text { allele TC }(200,264,427)(\%)\end{array}$} & \multirow[t]{2}{*}{ p value } \\
\hline & Male & Female & & Male & Female & & Male & Female & \\
\hline Patients & $10(52.63)$ & $9(47.37)$ & $0.328 \mathrm{NS}$ & $0(0.00)$ & $0(0.00)$ & $1.00 \mathrm{NS}$ & $20(48.78)$ & $21(51.22)$ & $0.573 \mathrm{NS}$ \\
\hline Controls & $0(0.00)$ & $0(0.00)$ & $1.00 \mathrm{NS}$ & $0(0.00)$ & $0(0.00)$ & $1.00 \mathrm{NS}$ & $30(50.00)$ & $30(50.00)$ & $1.00 \mathrm{NS}$ \\
\hline $\mathrm{p}$ value & $0.0001^{* *}$ & $0.0001^{* *}$ & - & $1.00 \mathrm{NS}$ & $1.00 \mathrm{NS}$ & --- & $0.804 \mathrm{NS}$ & $0.804 \mathrm{NS}$ & \\
\hline
\end{tabular}

$* * \mathrm{p}<0.01$, NS: Non-significant 
control groups for both sexes. 60 healthy individuals (100\%) of total participants were used in this study and had present $\mathrm{rs} 2236722 \mathrm{~T}<\mathrm{C}$ polymorphism amplification, whereas the distribution of genotype TC was (60) $100 \%$, and 60 patients (100\%) had present rs2236722 $\mathrm{T}<\mathrm{C}$ polymorphism amplification, whereas the distribution of genotype TT was (19) $31.67 \%$ and the distribution of genotype TC was (41) $68.33 \%$. The frequency of homozygote $\mathrm{T}$ allele in the present study of patients was 0.66 , which was higher than the frequency of homozygote $\mathrm{T}$ allele of control was 0.50 , while the frequency of heterozygote $C$ allele in the present study of patients was 0.34 , which was lower than the frequency of heterozygote $\mathrm{C}$ allele of control was 0.50 .

To measure 95\% CI and OR for acromegaly risk, different comparisons of rs2236722 alleles additionally analyzed C versus $\mathrm{T}$ alleles as shown in Table 4. The particular acromegaly subpopulations' OR for CC versus TT and TC versus TT alleles additionally CC versus TC alleles was estimated. The patients with acromegaly OR for CC versus TT and TC versus TT patients was $1.28(0.96-1.61,95 \% \mathrm{CI})$. Hence, in this group, the TT allele tended to be correlated with an elevated acromegaly risk as indicated through $\mathrm{OR}>1$, although these differences were significant, while the OR for healthy control for TT versus TC and CC versus TC individuals was 2.00 (0.96-1.61, 95\% $\mathrm{CI})$. Hence, in this group, the TC allele tended to be correlated with a decreased acromegaly risk as indicated through $\mathrm{OR}>1$, the differences were significant.

\section{Correlation between genotypes and aromatase activity}

This research concludes to the aromatase enzyme activity measurement in serum for acromegaly patients and healthy controls and compares the results to their alleles. The results detected in aromatase activity were a significant decrease $(p \leq 0.01)$ in acromegaly relation to the control group. Table 5 shows that the activity of aromatase was a significant decrease $(p \leq 0.05)$ in patients carrying TC allele of both rs10046 and rs2236722 contrasted to individual that had the same alleles in healthy control group. While between the two groups, the activity of other alleles did not seen any significant.

Table 3: Distribution of gene polymorphism and allele frequency in patients and controls

\begin{tabular}{lll}
\hline \multirow{2}{*}{ Genotype } & $\mathbf{n}(\%)$ & \\
\cline { 2 - 3 } & Patients & Healthy \\
\hline TT & $19(31.67)$ & $0(0.00)$ \\
TC & $41(68.33)$ & $60(100)$ \\
CC & $0(0.00)$ & $0(0.00)$ \\
Total & $60(100)$ & $60(100)$ \\
Chi-square value $\left(\chi^{2}\right)$ & $8.923^{* *}$ & $15.00^{* *}$ \\
Allele frequency & & \\
T & 0.66 & 0.50 \\
C & 0.34 & 0.50 \\
Total & $1(100)$ & $1(100)$ \\
\hline$* *$ p $<0.01$ & &
\end{tabular}

Table 4: OR, P values, and 95\% confidence intervals for the correlated with CYP19A1 (rs2236722) alleles with acromegaly risk

\begin{tabular}{|c|c|c|c|c|}
\hline Allele & Number of patients (\%) & Compared genotypes & OR & $95 \% \mathrm{CI}$ \\
\hline TC & $41(68.33)$ & CC vs. TT & 1.28 & $(0.96-1.61)$ \\
\hline $\mathrm{TT}$ & $19(31.67)$ & TC vs. TT & 1.28 & $(0.96-1.61)$ \\
\hline CC & $0(0.00)$ & CC vs. TC & 1.63 & $(0.93-1.61)$ \\
\hline Chi-square value $\left(\chi^{2}\right)$ & $8.923^{* *}$ & & & \\
\hline Allele & Number of healthy (\%) & Compared genotypes & OR & $95 \% \mathrm{CI}$ \\
\hline $\mathrm{CC}$ & $0(0.00)$ & CC vs. TC & 2.00 & $(0.96-1.61)$ \\
\hline $\mathrm{TC}$ & $60(100)$ & CC vs. TT & 0.00 & $(0.96-1.61)$ \\
\hline Chi-square value $\left(\chi^{2}\right)$ & $15.00 * *$ & & & \\
\hline
\end{tabular}

OR: Odds ratios, CYP19A1: cytochrome P450, superfamily19, polypeptide 1, CI: Confidence intervals, **: p<0.01

This is the first study in the world that investigated the correlation of CYP19A1 gene polymorphisms with the acromegaly. We accurately limited the study people to the Iraqi people in the areas of Baghdad city to keep up genetic homogeneity between the people furthermore to avert the confusing effects of environmental factors and interracial differences of genetic backgrounds, such as living behaviors. The current study investigates the aromatase activity and polymorphism of CYP19A1 genes among 60 apparently healthy and 60 active acromegaly patients from different regions of Baghdad metropolis; the association among the CYP19A1 gene polymorphisms and various factors was studied. Then, the CYP19 polymorphism sites were chosen in public databases (http://www.ncbi.nlm.nih.gov/snp/). Our research was shown that there was associated between CYP19 gene polymorphism (rs2236722) with aromatase activity and related to acromegaly in Iraqi patients. We found there was the statistically significant correlation between the aromatase enzyme activity and the existence of the allele, that's mean the decrease of aromatase enzyme activity demonstrates lead to increased presence of an allele or that allele is satisfactory allele and the individual has acromegaly disease, also we can distinguish between of patients and healthy samples especially when the appearance of TC allele by measuring the activity of the enzyme, therefore, can diagnosis the disease. In this comprehension in human biology, the role of aromatase has been promoted through a few individual situation statements of the patients with complete aromatase deficiency [13]. The previous studies like Lin et al. explain that aromatase mutations can make in humans variable or "nonclassic" phenotypes. At puberty, little residual aromatase activity may be adequate for the breast and uterine development to occur, in spite of important androgenization in utero. That phenotypic variability may be affected further by modifying factors such as variability in coregulators, non-classic pathways of estrogen synthesis, or differences in androgen responsiveness propose an important modulatory function for this enzyme in metabolic function and endocrine within the broader population [14].

Based on our previous assessment, our analysis in this study evaluated whether inter-individual variation in the CYP19A1 gene alters susceptibility to acromegaly conditions in Iraqi patients. The overall risk of either disease outcome was related to the individual genotypes since the risk of acromegaly associated with several gene variants differed according to proliferation status. While another study by Ledan et al. shows that the variation in the CYP19A1 gene alters capability to fibrocystic breast or breast cancer conditions in Chinese women. In our study, our analysis revealed a significant association between polymorphism rs2236722 and acromegaly related to a deficiency in aromatase activity. In agreement with this suggestion, breast cancer, infertility, and endometriosis studies have found that patients related with this polymorphism. The overall risk of either disease outcome was not related to any of the individual genotypes or block-specific haplotypes although the risk of breast cancer correlated with several gene variants differed according to proliferation status. The observed 
Table 5: Comparison of aromatase activity between acromegaly and control according to genotypes

\begin{tabular}{llllll}
\hline $\begin{array}{l}\text { Allele } \\
\text { genotype }\end{array}$ & $\begin{array}{l}\text { Aromatase activity }(\mathrm{ng} / \mathrm{mL}) \\
\text { mean } \pm \text { SD }\end{array}$ & t-test & p value \\
\cline { 2 - 4 } & Gender & Patient & Control & & \\
\hline $\mathrm{TT}$ & $\mathrm{M}$ & $2.879 \pm 0.87$ & - & 9.23 & $0.0000^{*}$ \\
& $\mathrm{~F}$ & $3.189 \pm 0.64$ & - & 11.92 & $0.0000^{*}$ \\
$\mathrm{TC}$ & $\mathrm{M}$ & $1.478 \pm 0.72$ & $11.303 \pm 0.28$ & -49.66 & $0.0000^{*}$ \\
& $\mathrm{~F}$ & $1.038 \pm 0.26$ & $23.293 \pm 0.002$ & -189.62 & $0.0000^{*}$ \\
\hline
\end{tabular}

**Significant difference: $\mathrm{p}<0.05$, SD: Standard deviation

increases in risk among breast cancer cases with, but not without, synchronous proliferative fibrocystic status indicate that CYP19A1 variation may only influence breast cancer etiology in this particular subgroup of women [15]. Moreover, another study by Chen et al. (2008) found that the elevated hazard of breast cancer with proliferative fibrocystic status about individual CYP19A1 markers was pronounced among women who were post-menopausal or had a BMI $\geq 23 \mathrm{~kg} / \mathrm{m}^{2}$. They observed could be explained by chance due to the number of analyses conducted and comparisons made; there are data to suggest that the chromosomal region 15q21.1, where CYP19A1 is located, may influence breast cancer progression [12]; likewise, the other studies by Kristensen et al. showed that the examined CYP19 polymorphisms (rs700518: A>G,rs2236722: T>C, [TTTA]n repeat, and rs10046: T>C) were not significantly correlated with the hazard of infertility and endometriosis or endometriosis with ovarian chocolate cysts in Chinese women [16]. Many prior studies from Korean people [17], Japanese people [18], and Caucasian people [19], all of that showed no significant correlation of CYP19 gene polymorphisms with the hazard of chocolate cysts or endometriosis. The study by Hirose et al., [20] showed that in estrogen biosynthesis, the genetic polymorphisms (CYP19A1) are as well expected to affect the degradation or synthesis of estrogen, and then, lead to increase the breast cancer risk at codon 39 [21,22], the (rs2236722) polymorphism is created by the substitution of amino acids (Trp) with (Arg), while another study showed the Japanese women with the presence of these different alleles (Arg) lead to significantly decreased the developing of the breast cancer risk [23]. In a survey by Leporati et al., the authors deal with the male patients with breast cancer and acromegaly. The breast cancer clinical course was closely concerning to the metabolic monitoring of acromegaly. The rapid metastatic lesion progression was temporally concerning to stopping treatment by pegvisomant and paralleled an increasing in serum levels of IGF-1. Normalization of serum IGF-1 levels after restarting pegvisomant impressively decreased the metastatic breast lesions progression. Acromegaly control is compulsory in acromegalic patients with cancer and evaluated the function of AIP mutations, which occur in pituitary adenomas, in the common genesis types of cancer (breast, prostate, and colorectal cancer) [24]. The studies by Surekha et al. showed that the aromatase gene expression is regulated in a tissue promoter I.4 governs particular manner and in adipose tissue expression [25], while Belgorosky et al. suggested that the lower of aromatase activity leads to the degree of masculinization of the external genitalia was greater at birth in females that exposure to an excess of androgens resulted in a changeable virilization of the mother and masculinization of the external genitalia since about $1 \%$ of the activity of placental aromatase of wild-type aromatase enzyme appears to be enough to prevent the mother virilization during pregnancy. Moreover, the absence of estrogen synthesis because of complete aromatase activity deficiency resulted in increased concentration of essential FSH $[26,27]$. Based on previous results, we in our analysis expand and refine previous results (including our own) by identifying a number of variables that predict and expected the present deficits in function of aromatase activity in those patients. In the current work, we suggested that once this correlation is confirmed by the biological importance of aromatase enzyme and illustrated through functional studies and this polymorphism could be a probable target for the early treatment and prevention of acromegaly.

\section{CONCLUSION}

This is the first study in the world investigating to found the correlation between of CYP19A1 gene polymorphisms and aromatase enzyme activity in the acromegaly disease. Proved the TT and TC genotypes tended to be correlated with an increased acromegaly risk where the relationship between rs2236722 SNP and aromatase enzyme activity was as following, whenever found the TT or TC genotypes and deficiency in aromatase enzyme activity that means there was active acromegaly disease, while in healthy individuals found the TC genotype but with normal enzyme activity, therefore, we can distinguish between of patients and healthy individuals and diagnosis the disease.

\section{ACKNOWLEDGMENTS}

The authors would like to thank all people who provided their blood sample and approval for genetic analysis

\section{REFERENCES}

1. Fougner SL, Bollerslev J, Svartberg J, Øksnes M, Cooper J, Carlsen SM. Preoperative octreotide treatment of acromegaly: Long-term results of a randomised controlled trial. Eur J Endocrinol 2014;171(2):229-35.

2. Katznelson L, Laws ER Jr, Melmed S, Molitch ME, Murad MH, Utz A, et al. Acromegaly: An endocrine society clinical practice guideline. J Clin Endocrinol Metab 2014;99(11):3933-51.

3. Koleva DI, Orbetzova MM, Atanassova PK. Adipose tissue hormones and appetite and body weight regulators in insulin resistance. Folia Med (Plovdiv) 2013;55(1):25-32.

4. Nagar S, Saha A. Qsar moeling and pharmacophore mapping of isoflavone derivatives for aromatase inhibitory activity. Int J Pharm Pharm Sci 2010;2 Suppl 3:126-31.

5. Selek A, Cetinarslan B, Gurbuz Y, Tarkun I, Canturk Z, Cabuk B. Aromatase enzyme expression in acromegaly and its possible relationship with disease prognosis. Endocrine 2015;49:250-7.

6. Zhao Y, Agarwal VR, Mendelson CR, Simpson ER. Estrogen biosynthesis proximal to a breast tumor is stimulated by PGE2 via cyclic AMP, leading to activation of promoter II of the CYP19 (aromatase) gene. Endocrinology 1996;137(12):5739-42.

7. Reed MJ, Purohit A. Aromatase regulation and breast cancer. Clin Endocrinol (Oxf) 2001;54(5):563-71.

8. Boone SD, Baumgartner KB, Baumgartner RN, Connor AE, Pinkston CM, Rai SN, et al. Associations between CYP19A1 polymorphisms, Native American ancestry, and breast cancer risk and mortality: The breast cancer health disparities study. Cancer Causes Control 2014;25(11):1461-71.

9. Lephart ED. Modulation of aromatase by phytoestrogens. Hindawi Publ Corp Enzyme Res 2015;2015:11.

10. Di Nardo G, Gilardi G. Human aromatase: Perspectives in biochemistry and biotechnology. Biotechnol Appl Biochem 2013;60(1):92-101.

11. Olin JL, St Pierre M. Aromatase inhibitors in breast cancer prevention. Ann Pharmacother 2014;48(12):1605-10.

12. Chen C, Sakoda LC, Doherty JA, Loomis MM, Fish S, Ray RM, et al. Genetic variation in CYP19A1 and risk of breast cancer and fibrocystic breast conditions among women in Shanghai, China. Cancer Epidemiol Biomarkers Prev 2008;17(12):3457-66.

13. Fasching PA, Loehberg CR, Strissel PL, Lux MP, Bani MR, Schrauder M, et al. Single nucleotide polymorphisms of the aromatase gene (CYP19A1), HER2/neu status, and prognosis in breast cancer patients. Breast Cancer Res Treat 2008;112(1):89-98.

14. Lin L, Ercan O, Raza J, Burren CP, Creighton SM, Auchus RJ, et al. Variable phenotypes associated with aromatase (CYP19) insufficiency in humans. J Clin Endocrinol Metab 2007;92(3):982-90.

15. Wang L, Lu X, Wang D, Qu W, Li W, Xu X. CYP19 gene variant confers susceptibility to endometriosis-associated infertility in Chinese women. Exp Mol Med 2014;46(6):e103.

16. Kristensen VN, Harada N, Yoshimura N, Haraldsen E, Lonning PE, Erikstein B, et al. Genetic variants of CYP19 (aromatase) and breast cancer risk. Oncogene 2000;19(10):1329-33.

17. Hur SE, Lee S, Lee JY, Moon HS, Kim HL, Chung HW. Polymorphisms and haplotypes of the gene encoding the estrogen-metabolizing CYP19 gene in Korean women: No association with advanced-stage endometriosis. J Hum Genet 2007;52(9):703-11.

18. Kado N, Kitawaki J, Obayashi H, Ishihara H, Koshiba H, Kusuki I, et al. Association of the CYP17 gene and CYP19 gene polymorphisms 
with risk of endometriosis in Japanese women. Hum Reprod 2002;17(4):897-902.

19. Trabert B, Schwartz SM, Peters U, De Roos AJ, Chen C, Scholes D, et al. Genetic variation in the sex hormone metabolic pathway and endometriosis risk: An evaluation of candidate genes. Fertil Steril 2011;96(6):1401-6.e3.

20. Hirose K, Matsuo K, Toyama T, Iwata H, Hamajima N, Tajima K. The CYP19 gene codon $39 \mathrm{Trp} /$ Arg polymorphism increases breast cancer risk in subsets of premenopausal Japanese. Cancer Epidemiol Biomarkers Prev 2004;13(8):1407-11.

21. Huang CS, Kuo SH, Lien HC, Yang SY, You SL, Shen CY, et al. The CYP19 TTTA repeat polymorphism is related to the prognosis of premenopausal stage I-II and operable stage III breast cancers. Oncologist 2008;13(7):751-60.

22. Miyoshi Y, Ando A, Hasegawa S, Ishitobi M, Yamamura J, Irahara N, et al. Association of genetic polymorphisms in CYP19 and CYP1A1 with the oestrogen receptor-positive breast cancer risk. Eur J Cancer 2003;39(17):2531-7.
23. Hamaguchi M, Nishio M, Toyama T, Sugiura H, Kondo N, Fujii Y, et al. Possible difference in frequencies of genetic polymorphisms of estrogen receptor $\alpha$, estrogen metabolism, and P53 genes between estrogen receptor-positive and negative breast cancers. Jpn J Clin Oncol 2008;38(11):734-42.

24. Leporati P, Fonte R, de Martinis L, Zambelli A, Magri F, Pavesi L, et al. A male patient with acromegaly and breast cancer: Treating acromegaly to control tumor progression. BMC Cancer 2015;15:397.

25. Surekha D, Sailaja K, Rao DN, Padma T, Raghunadharao D, Vishnupriya S. Association of CYP19 polymorphisms with breast cancer risk: A case-control study. J Nat Sci Biol Med 2014;5(2):250-4

26. Belgorosky A, Guercio G, Pepe C, Saraco N, Rivarola MA. Genetic and clinical spectrum of aromatase deficiency in infancy, childhood and adolescence. Horm Res 2009;72(6):321-30.

27. Paul CB, Sudaniradoss C. Aromatase inhibiters-types and advantages. Int J Pharm Pharm Sci 2016;8(8):1-7. 